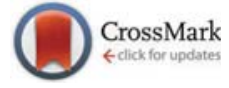

Cite this: Phys. Chem. Chem. Phys., $2014,16,21230$

Received 21st August 2014, Accepted 29th August 2014

DOI: $10.1039 / c 4 c p 03758 h$

www.rsc.org/pccp

\section{Controlled CO release using photochemical, thermal and electrochemical approaches from the amino carbene complex $\left[(\mathrm{CO})_{5} \mathrm{CrC}\left(\mathrm{NC}_{4} \mathrm{H}_{8}\right) \mathrm{CH}_{3}\right] \dagger$}

\author{
Suzanne McMahon, ${ }^{a}$ Jonathan Rochford, ${ }^{b}$ Yvonne Halpin, ${ }^{a}$ Jennifer C. Manton, ${ }^{a}$ \\ Emma C. Harvey, ${ }^{a}$ Gregory M. Greetham, ${ }^{c}$ Ian P. Clark, ${ }^{c}$ A. Denise Rooney, ${ }^{d}$ \\ Conor Long a and Mary T. Pryce*a
}

\begin{abstract}
Multimodal photo, thermal and electrochemical approaches toward $\mathrm{CO}$ release from the amino carbene complex $\left[(\mathrm{CO})_{5} \mathrm{CrC}\left(\mathrm{NC}_{4} \mathrm{H}_{8}\right) \mathrm{CH}_{3}\right]$ is reported. Picosecond time resolved infrared spectroscopy was used to probe the photo-induced early state dynamics leading to $C O$ release, and DFT calculations confirmed that $C O$ release occurs from a singlet excited state.
\end{abstract}

CO releasing molecules (CORMs) are an area of current interest due to the physiological role of $\mathrm{CO}$ in the body., ${ }^{1,2} \mathrm{CO}$ is endogenously generated during oxidative heme degradation by the heme oxygenase (HO) enzymes. ${ }^{3}$ The potential therapeutic applications of CO include vasodilation, anti-inflammatory and anti-proliferative effects. CORMs have been developed to deliver $\mathrm{CO}$ in a controlled manner. However, there is a major challenge in controlled CO release, be it photochemically, thermally or enzymatically induced. It is well known that chromium carbene complexes can release CO both thermally and photochemically, as the resulting tetracarbonyl reactive intermediates have been used as synthons in organic chemistry. ${ }^{4}$ Recently, Lynam et al. reported the suitability of heteroatom (amino, methoxy and thio) stabilised chromium carbenes as thermal CORMs. ${ }^{5}$ Rapid CO release was observed for the thio- and methoxy carbenes $\left(t_{1 / 2}=\right.$ $313 \mathrm{~s}$ and $306 \mathrm{~s}$, respectively, for a $60 \mu \mathrm{M}$ solution of the complex to achieve an Mb-CO concentration of $30 \mu \mathrm{M}$ ), compared to slow release in the case of the amino analogue which required more than $2 \mathrm{~h}$ for a $60 \mu \mathrm{M}$ solution of the complex to form $10 \mu \mathrm{M}$ of carboxy-myoglobin (Mb-CO). In addition the chromium carbonyls investigated, demonstrated the fastest and most regulated $\mathrm{CO}$

\footnotetext{
${ }^{a}$ School of Chemical Sciences, Dublin City University, Dublin 9, Ireland.

E-mail: mary.pryce@dcu.ie; Fax: +3531700 5503; Tel: +35317008005

${ }^{b}$ Department of Chemistry, University of Massachusetts Boston,

100 Morrissey Boulevard, Boston, Massachusetts 02125, USA

${ }^{c}$ Central Laser Facility, Science \& Technology Facilities Council,

Rutherford Appleton Laboratory, Harwell Science and Innovation Campus, Didcot, OX11 OQX, UK

${ }^{d}$ Chemistry Department, National University of Ireland Maynooth, Co. Kildare, Ireland

$\dagger$ Electronic supplementary information (ESI) available. See DOI: 10.1039/c4cp03758h
}

release characteristics compared to the molybdenum or tungsten complexes studied. ${ }^{5}$

In this communication we set out to compare the rate of $\mathrm{CO}$ release from $\left[(\mathrm{CO})_{5} \mathrm{CrC}\left(\mathrm{NC}_{4} \mathrm{H}_{8}\right) \mathrm{CH}_{3}\right]$ using photochemical, thermal and electrochemical stimulation. To the best of our knowledge this is first example of a CORM involving electrochemical stimulation. In the present study we report our findings on a ps-time resolved infrared (ps-TRIR) study on $\left[(\mathrm{CO})_{5} \mathrm{CrC}\left(\mathrm{NC}_{4} \mathrm{H}_{8}\right) \mathrm{CH}_{3}\right]$ in conjunction with DFT calculations to investigate the excited state responsible for the $\mathrm{CO}$ release. Chromium Fischer carbenes have received significant attention as photochemical synthons for a range of organic compounds. Photolysis of $\left[(\mathrm{CO})_{5} \mathrm{CrC}(\mathrm{XR}) \mathrm{R}^{\prime}\right]$ in the presence of imines, olefins, aldehydes, or alcohols are known to yield $\beta$-lactams, cyclobutanones, $\beta$-lactones or amino esters respectively. ${ }^{6}$ The proposed mechanism for these reactions involves a metal-toligand charge transfer photoexcitation resulting in the formation of a ketene intermediate which is formed by the insertion of a cis-CO ligand into the adjacent $\mathrm{Cr}-$ carbene bond (Fig. 1). Experimental and theoretical calculations reported by Sierra et al. support the proposal that this occurs through a MLCT triplet excited state. ${ }^{7}$

Although a number of low temperature and time-resolved studies have investigated photo-induced $\mathrm{CO}$ release from chromium carbenes, ${ }^{8-10}$ no previous data have been reported on the picosecond time scale or on using modern theoretical calculations to identify the nature of the excited state involved in $\mathrm{CO}$ release.

The CO-releasing ability of $\left[(\mathrm{CO})_{5} \mathrm{CrC}\left(\mathrm{C}_{4} \mathrm{H}_{8} \mathrm{~N}\right) \mathrm{CH}_{3}\right]$ was determined both photochemically using $355 \mathrm{~nm}$ (LED) excitation and thermally (at $37{ }^{\circ} \mathrm{C}$ ) using a myoglobin (Mb) assay. ${ }^{2,11}$ Fig. 2 illustrates the $\mathrm{CO}$ release profile for the photo activated CORM.

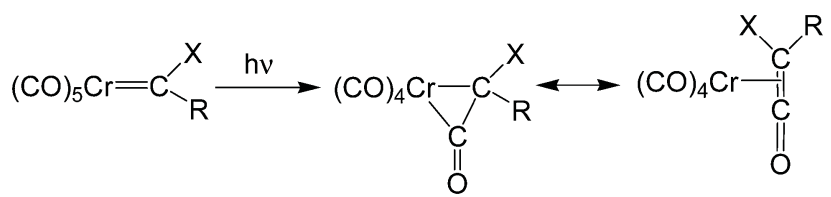

Fig. 1 Chromium-ketene intermediate proposed following photolysis of $\left[(\mathrm{CO}){ }_{5} \mathrm{CrC}(\mathrm{XR}) \mathrm{R}^{\prime}\right] . \mathrm{X}=$ amino, alkoxy, and $\mathrm{R}=$ alkyl, aryl, $\mathrm{H}$. 


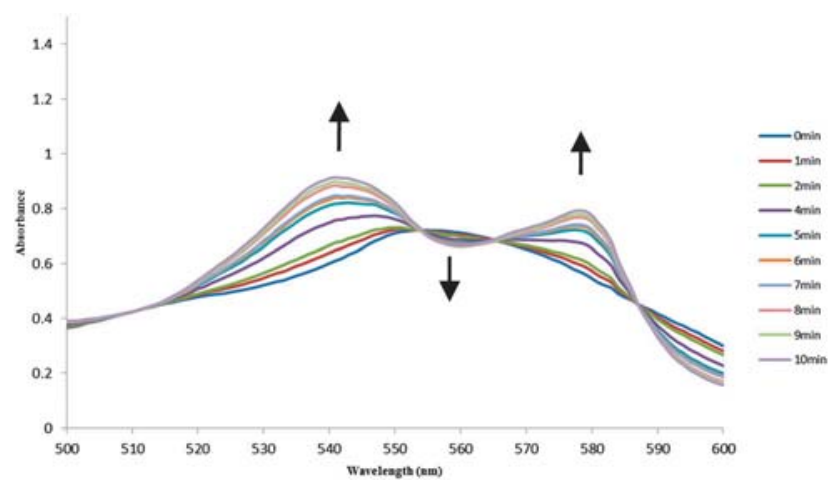

Fig. $2 \mathrm{CO}$ release profile for $\left[(\mathrm{CO})_{5} \mathrm{CrC}\left(\mathrm{NC}_{4} \mathrm{H}_{8}\right) \mathrm{CH}_{3}\right](60 \mu \mathrm{M})$ measuring the conversion of deoxy-Mb to $\mathrm{Mb}-\mathrm{CO}$ against time, photochemically at $355 \mathrm{~nm}$, see $\mathrm{ESI} \dagger$ for experimental conditions.

During the experiments the intensity of the Mb Q-band at $\sim 554 \mathrm{~nm}$ decreases while the characteristic peaks of Mb-CO appears at $540 \mathrm{~nm}$ and $578 \mathrm{~nm}$ (indicated by the arrows in Fig. 2). The major notable difference between the two methods employed for CO release is the difference in $t_{1 / 2}$ values. Complete saturation of deoxy-Mb by $\left[(\mathrm{CO})_{5} \mathrm{CrC}\left(\mathrm{C}_{4} \mathrm{H}_{8} \mathrm{~N}\right) \mathrm{CH}_{3}\right]$ was observed, but required $\sim 3 \mathrm{~h}$ at $37{ }^{\circ} \mathrm{C}(60 \mu \mathrm{M}),\left(t_{1 / 2}=4544 \mathrm{~s}\right)$. This is significantly slower than that observed photochemically where $t_{1 / 2}=266 \mathrm{~s}$.

Electrochemical analysis of $\left[(\mathrm{CO})_{5} \mathrm{CrC}\left(\mathrm{NC}_{4} \mathrm{H}_{8}\right) \mathrm{CH}_{3}\right]$ in $0.1 \mathrm{M}$ $\mathrm{TBAPF}_{6}$ in acetonitrile using cyclic voltammetry reveals three redox processes within the potential window investigated (Fig. 3). These include two oxidative processes and one reductive process $\left(+0.34 \mathrm{~V},+1.03 \mathrm{~V}\right.$ and $-2.80 \mathrm{~V}$ vs. $\left.\mathrm{Fc} / \mathrm{Fc}^{+}\right)$. The first oxidation is assigned to the $\mathrm{Cr}^{0 / \mathrm{I}}$ redox couple as previously reported. ${ }^{12,13}$ Oxidation of these types of metal carbene complexes is reported as being predominantly metal based ${ }^{12}$ with reduction centred on the metal-carbene double bond, consistent with the HOMO and LUMO images illustrated in ESI, $\dagger$ Fig. S7. ${ }^{13}$ Varying scan rates did not promote reversibility for the redox processes observed. In vivo studies using electrochemical methods as potential therapeutics for diseases such as cancer have been reported in the literature. ${ }^{14-16}$ In the present study, electrochemical initiation of CO-release from the complex was confirmed and quantified via headspace analysis using gas chromatography

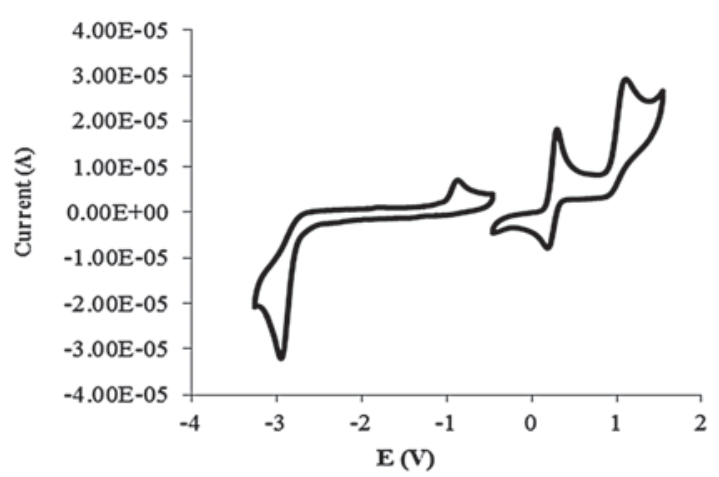

Fig. 3 Cyclic voltammogram of oxidation and reduction of $\left[(\mathrm{CO})_{5} \mathrm{CrC}\right.$ $\left.\left(\mathrm{NC}_{4} \mathrm{H}_{8}\right) \mathrm{CH}_{3}\right]$ in $0.1 \mathrm{M} \mathrm{TBAPF}_{6}$ in $\mathrm{CH}_{3} \mathrm{CN}$, vs. Fc/Fc . Scan rate $=0.1 \mathrm{~V} \mathrm{~s}^{-1}$

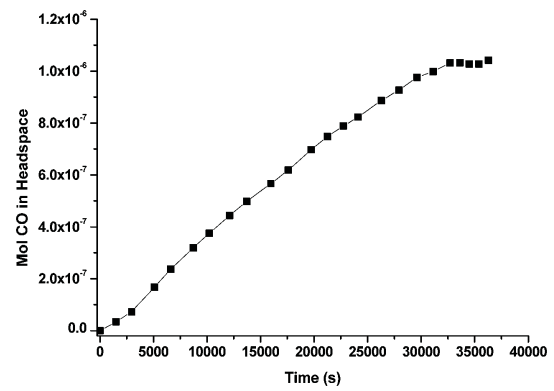

Fig. 4 Profile for the electrochemically induced $\mathrm{CO}$ release over time from $\left[(\mathrm{CO})_{5} \mathrm{CrC}\left(\mathrm{NC}_{4} \mathrm{H}_{8}\right) \mathrm{CH}_{3}\right]$ in acetonitrile under potentiostatic conditions $\left(E=+0.36 \mathrm{~V}\right.$ vs. $\left.\mathrm{Fc} / \mathrm{FC}^{+}\right)$. Concentration of $\left[(\mathrm{CO})_{5} \mathrm{CrC}\left(\mathrm{NC}_{4} \mathrm{H}_{8}\right) \mathrm{CH}_{3}\right]$ was $0.1 \mathrm{mM}$ and the solution was stirred continuously.

(ESI, $\dagger$ Fig. S6). Displayed in Fig. 4 is the electrochemical CO-release profile over 10 hours of controlled potential electrolysis $(E=+0.36 \mathrm{~V})$. The concentration of $\mathrm{CO}$ in the headspace suggests loss of one CO molecule per Fischer carbene centre. As one-electron oxidation of $\left[(\mathrm{CO})_{5} \mathrm{CrC}\left(\mathrm{NC}_{4} \mathrm{H}_{8}\right) \mathrm{CH}_{3}\right]$ is primarily characterised by the $\operatorname{Cr}(\mathrm{I} / 0)$ couple, it is likely that the reduced capacity of $\operatorname{Cr}(\mathrm{I})$ for $\pi$ back-donation likely results in a more labile $\mathrm{Cr}-\mathrm{CO}$ bond. To the best of our knowledge this is the first report where electrochemically initiated CO loss from a CO-RM has been quantified.

Since photochemically CO release is significantly faster than the thermal approach, the early state dynamics leading to CO loss following excitation of $\left[(\mathrm{CO})_{5} \mathrm{CrC}\left(\mathrm{C}_{4} \mathrm{H}_{8} \mathrm{~N}\right) \mathrm{CH}_{3}\right]$ at $400 \mathrm{~nm}$ was probed using pico-second TRIR (see ESI for experimental conditions). The IR spectrum of the parent $\left[(\mathrm{CO})_{5} \mathrm{CrC}\left(\mathrm{NC}_{4} \mathrm{H}_{8}\right) \mathrm{CH}_{3}\right]$ complex in $n$-heptane exhibits metal carbonyl stretching bands at 2055,1967 , and $1928 \mathrm{~cm}^{-1}$. The spectral changes observed following pulsed (50 fs) excitation of $\left[(\mathrm{CO})_{5} \mathrm{CrC}\left(\mathrm{NC}_{4} \mathrm{H}_{8}\right) \mathrm{CH}_{3}\right]$ at $400 \mathrm{~nm}$ are presented in Fig. $5 .^{17}$ The spectrum obtained 3 ps after excitation shows depletion of the parent bands as the negative features in the difference spectrum. New bands at 2016, 1913 and $1897 \mathrm{~cm}^{-1}$ are formed within this timescale and these are assigned to an excited state species. Over the subsequent 50 ps these bands decay with concomitant formation

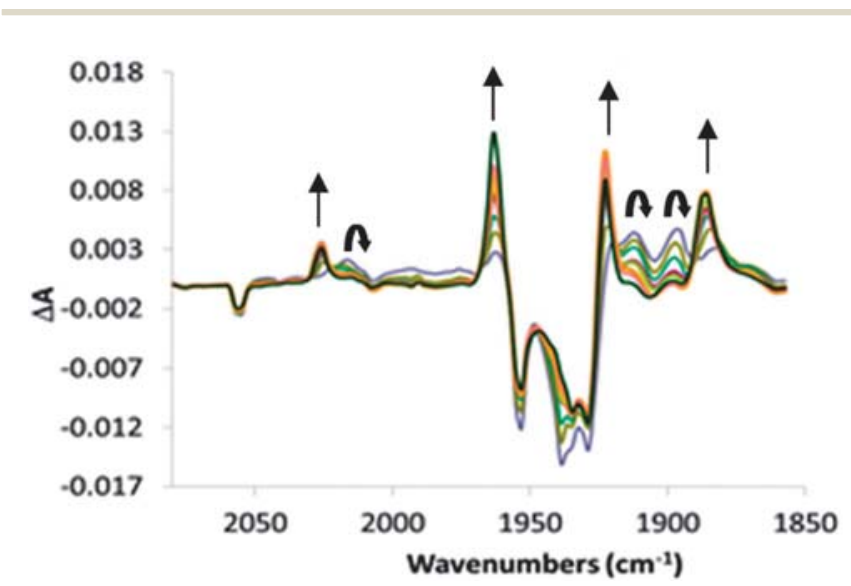

Fig. 5 Picosecond TRIR difference spectra following $400 \mathrm{~nm}$ photolysis of [ $\left.(\mathrm{CO})_{5} \mathrm{CrC}\left(\mathrm{NC}_{4} \mathrm{H}_{8}\right) \mathrm{CH}_{3}\right]$ in $n$-heptane solution at selected time intervals; $4,12,21,37,44,68,90,1000$ ps. 
of bands at 2025, 1963, 1923 and $1886 \mathrm{~cm}^{-1}$. These bands are assigned to the solvated species, [(heptane) $\left.(\mathrm{CO})_{4} \mathrm{CrC}\left(\mathrm{NC}_{4} \mathrm{H}_{8}\right) \mathrm{CH}_{3}\right]$ and are consistent with the bands previously reported for the $\mathrm{CO}$ loss species in low temperature matrices at $20 \mathrm{~K} .{ }^{9}$ The extent of parent band recovery provides an estimate of the overall quantum yield for the CO-loss process of 0.65 . No evidence for the ketene intermediate proposed in Fig. 1 was found in this study.

$\left[(\mathrm{CO})_{5} \mathrm{CrC}\left(\mathrm{NC}_{4} \mathrm{H}_{8}\right) \mathrm{CH}_{3}\right]$ was modelled using a hybrid Density Functional Theory (B3LYP) ${ }^{18,19}$ using a triple zeta quality basis set (Tzvp) ${ }^{20}$ as implemented in Gaussian 09 (Revision D.01). ${ }^{21}$ Full details are provided in the ESI. $\dagger$ The $\mathrm{Cr}$-cisCO distance was chosen as a suitable reaction coordinate to model the CO loss reaction. A relaxed potential energy scan was preformed along this reaction coordinate and at each point time-dependent DFT calculations provided the vertical excitation energies to the five lowest energy singlet excited states (TDDFT/B3LYP/Tzvp). These data were then used to construct an energy profile along this reaction coordinate for these excited states (Fig. 6). The plots confirm that $\mathrm{CO}$ can be liberated from the lowest energy singlet excited state (metal-to-carbene charge-transfer in character) by surmounting a small thermal barrier $\left(5.6 \times 10^{-4} \mathrm{~kJ} \mathrm{~mol}^{-1}\right)$, the latter formed by crossing with the 2 nd singlet excited state which is metal centred in character. Thus CO-loss from this system will be arrested compared to CO-loss from $\mathrm{Cr}(\mathrm{CO})_{6}$. In the case of $\operatorname{Cr}(\mathrm{CO})_{6}\left(\Phi_{\mathrm{CO}}=0.72\right)$, CO loss occurs on the ultrafast time scale $(<100 \mathrm{fs}) .{ }^{21}$ Along this reaction coordinate the $\mathrm{Cr}-\mathrm{CO}$ distance on only one cis CO is increased and consequently the symmetry and therefore the IR spectrum of the excited state will resemble that of the CO-loss product. The lowest energy singlet excited state has substantial metal-to-carbene charge-transfer character (ESI, $\dagger$ Fig. S9) while the second singlet excited state is mainly a metal-centred state (ESI, $\dagger$ Fig. S10). The DFT calculations reported here do not indicate the population of a triplet excited state.

In conclusion, we have identified three stimuli to induce CO-release from $\left[(\mathrm{CO})_{5} \mathrm{CrC}\left(\mathrm{NC}_{4} \mathrm{H}_{8}\right) \mathrm{CH}_{3}\right]$. Thus proving that, a single type of CORM can be used for either fast or slow CO release simply by altering the means of excitation. The ps-TRIR highlight that a singlet excited state yields CO loss within 50 ps

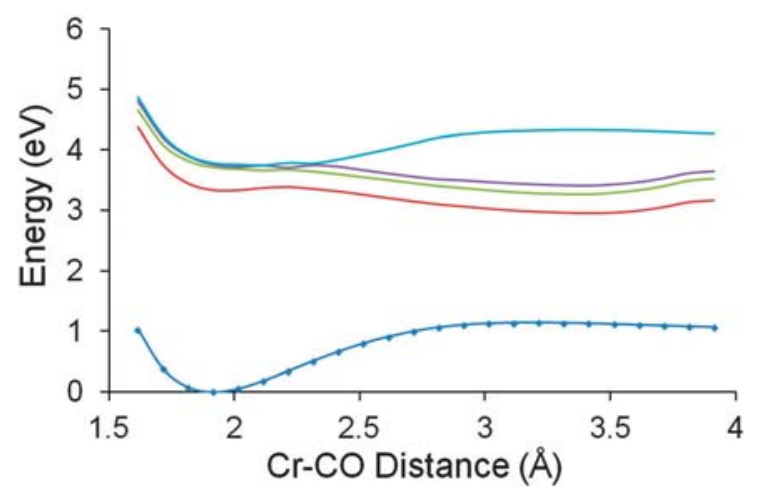

Fig. 6 The energy of the ground state (blue) and the four lowest energy singlet excited states as the $\mathrm{Cr}$-cisCO distance is varied, (the data interval is indicated by data point markers on the ground state curve but omitted from the excited state curves for clarity). which translates to a 17 -fold increase in the rate of CO-uptake by deoxy-Mb at $37{ }^{\circ} \mathrm{C}$ in phosphate buffered saline buffer when $t_{1 / 2}$ for both thermal and photochemical are compared. DFT calculations confirm a cis-CO ligand is expelled from the lowest energy excited state which has substantial metal-to-carbene charge-transfer character. Electrochemically, CO loss was detected and quantified at a low potential which is important for physiological applications. ${ }^{22,23}$ Current studies are in progress on water soluble analogues of Fischer carbene complexes.

\section{Acknowledgements}

The authors would like the Irish Research Council (RS/2012/341) (SM), Science Foundation Ireland (13/TIDA/E2763) (YH) and the Environmental Protection Agency (EPA grant 2008-ET-MS-3-S2) (JCM) for financial support. The authors also thank the Central Laser Facility for granting access to the ULTRA system under grant no. 92004 .

\section{Notes and references}

1 L. S. Nobre, J. D. Seixas, C. C. Romão and L. M. Saraiva, Antimicrob. Agents Chemother., 2007, 51, 4303-4307.

2 R. Motterlini, J. E. Clark, R. Foresti, P. Sarathchandra, B. E. Mann and C. J. Green, Circ. Res., 2002, 90, 17e-24e.

3 M. D. Maines, Annu. Rev. Pharmacol. Toxicol., 1997, 37, 517-554.

4 M. A. Schwindt, J. R. Miller and L. S. Hegedus, J. Organomet. Chem., 1991, 413, 143-153.

5 W.-Q. Zhang, A. C. Whitwood, I. J. S. Fairlamb and J. M. Lynam, Inorg. Chem., 2010, 49, 8941-8952.

6 L. S. Hegedus, Tetrahedron, 1997, 53, 4105-4128.

7 A. Arrieta, F. P. Cossio, I. Fernandez, B. Lecea, M. J. Mancheno and M. A. Sierra, J. Am. Chem. Soc., 2000, 122, 11509-11510.

8 P. C. Servaas, D. J. Stufkens and A. Oskam, J. Organomet. Chem., 1990, 390, 61-71.

9 M. L. Gallagher, J. B. Greene and A. D. Rooney, Organometallics, 1997, 16, 5260-5268.

10 K. O. Doyle, M. L. Gallagher, M. T. Pryce and A. D. Rooney, J. Organomet. Chem., 2001, 617, 269-279.

11 A. J. Atkin, J. M. Lynam, B. E. Moulton, P. Sawle, R. Motterlini, N. M. Boyle, M. T. Pryce and I. J. S. Fairlamb, Dalton Trans., 2011, 40, 5755-5761.

12 M. Landman, R. Liu, R. Fraser, P. H. van Rooyen and J. Conradie, J. Organomet. Chem., 2014, 752, 171-182.

13 I. Hoskovcová, J. Roháčová, L. Meca, T. Tobrman, D. Dvořák and J. Ludvík, Electrochim. Acta, 2005, 50, 4911-4915.

14 M. Tello, L. Oliveira, O. Parise, A. C. Buzaid, R. T. Oliveira, R. Zanella and A. Cardona, Proceedings of the 29th Annual International Conference of the IEEE EMBS, 2007, 3524-3527.

15 N. Olaiz, F. Maglietti, C. Suárez, F. V. Molina, D. Miklavcic, L. Mir and G. Marshall, Electrochim. Acta, 2010, 55, 6010-6014.

16 M. Breton and L. M. Mir, Bioelectromagnetics, 2012, 33, 106-123.

17 I. P. Clark, M. W. George, G. M. Greetham, E. C. Harvey, C. Long, J. C. Manton and M. T. Pryce, J. Phys. Chem. A, 2010, 114, 11425-11431. 
18 A. D. Becke, Phys. Rev. A: At., Mol., Opt. Phys., 1988, 38, 21 E. J. Baerends and A. Rosa, Coord. Chem. Rev., 1998, 177, 3098-3100. 97-125.

19 C. Lee, W. Yang and R. G. Parr, Phys. Rev. B: Condens. Matter Mater. Phys., 1988, 37, 785-789.

22 D. R. Merrill, M. Bikson and J. G. R. Jefferys, J. Neurosci. Methods, 2005, 141, 171-198.

20 A. Schafer, C. Huber and R. Ahlrichs, J. Chem. Phys., 1994, 23 S. F. Cogan, A. A. Guzelian, W. F. Agnew, T. G. H. Yuen and 100, 5829-5835.

D. B. McCreery, J. Neurosci. Methods, 2004, 137, 141-150. 